\title{
Effect of Smoking on FEF 25, FEF 50 \& FEF 75 in Adult Male Smokers
}

\author{
Shamima Akhter *1, Md. Ruhul Amin ${ }^{2}$, Md. Noor Nabi ${ }^{3}$, Nahid Yeasmin ${ }^{4}$, \\ Mahmudul Hasan ${ }^{5}$, Sharmin Nahar ${ }^{6}$, Rukhshana Rabbani ${ }^{7}$
}

\begin{abstract}
Introduction:Smoking is most common in East Asia, where two thirds of all adult males smoke tobacco; cigarette smoking is by far the most common. Smoking is the primary cause of chronic obstructive lung disease, chronic bronchitis and other respiratory symptoms. Many studies have shown significant changes of Forced Expiratory Flow (FEF) as FEF 25, FEF 50 and FEF 75 (L/sec) in adult male smokers. Its objective is to assess the change of FEF 25, FEF 50 and FEF 75 (L/sec) in adult male smokers. Materials and Methods: This cross-sectional comparative study was carried out in the Department of Physiology, Dhaka Medical College, Dhaka during the period of July, 2007 to June, 2008. In the present study 30 adult male smokers consuming cigarettes for more than 5 years selected as study group (Group-B) and were matched with 30 adult males who were non-smokers considered as control group (Group-A) for comparison. FEF 25, FEF 50 and FEF 75 $(\mathrm{L} / \mathrm{sec})$ were estimated in both Groups. Analysis of data was done with the help of computer by SPSS 12.0 programmer and significant tests were done by unpaired Student's " $t$ " test. Results: There were statistically significant differences of FEF25, FEF50 and FEF75 (L/sec) in group A vs. group B. Conclusion: From the statistical analysis of the results obtained in the present study and their comparison with those of published reports, it may be concluded that smoking causes significant change of FEF 25, FEF 50 and FEF 75 ( L/sec) among the smokers that could be useful in early diagnosis of peripheral airway obstruction.
\end{abstract}

Keywords: Forced Expiratory Flow, FEF 25, FEF 50, FEF 75, Smoking, Smoker.

Number of Tables: 02; Number of Figures: 03; Number of References: 18; Number of Correspondence: 05.

*1. Corresponding Author:

Dr. Shamima Akhter

Assistant Professor, Department of Physiology

Dhaka Medical College, Dhaka.

E-mail: nawafamuna@yahoo.com.

Mobile: 01711803395

2. Prof. Md. Ruhul Amin

Professor and Head, Department of Physiology

Shahabuddin Medical College, Dhaka.

3. Dr. Md. Noor Nabi

Lieutenant Colonel and Deputy Director

Medical Services, Bangladesh Coast Guard Head Quarter, Agargaon, Dhaka.

4. Dr. Nahid Yeasmin Assistant Professor, Department of Physiology Dhaka Medical College, Dhaka.

5. Dr. Mahmudul Hasan

Lecturer, Department of Physiology

Dhaka Medical College, Dhaka.

6. Dr. Sharmin Nahar

Lecturer, Department of Physiology

Dhaka Medical College, Dhaka.

7. Dr. Rukhshana Rabbani

Assistant Professor

Department of Radiotherapy

Dhaka Medical College, Dhaka.

\section{Introduction}

Cigarettes, the most popular method of smoking, consist of finely shredded tobacco rolled in light-weight paper. Smoke from the average cigarette contains around four thousand chemicals, some of which are highly toxic and at least 43 of which cause cancer. Nicotine, a major constituent of tobacco smoke is both poisonous and highly addictive ${ }^{1}$.

FEF25, FEF50 and FEF75 (L/sec) is the average flow rate over the middle of vital capacity. This test indicates the patency of smaller airways less than $2 \mathrm{~mm}$ in diameter ${ }^{2}$.

World deaths from cigarettes are expected to increase from three millions currently to about ten millions by the year 2020. As the market for tobacco shrinks in the developed nations, the multinational tobacco companies are targeting developing countries ${ }^{3}$.

It is estimated that 60 percent of men in Bangladesh are smokers ${ }^{4}$. Tobacco related illness accounts for $16 \%$ death in Bangladesh among people aged 30 years and above ${ }^{5}$. About 54\% lung cancer patients are habituated with current smoking and $74.04 \%$ were ever smoker in Bangladesh $^{6}$.

A few studies had been carried out in Bangladesh on the effect of smoking on lung function. This work will be done for finding out the risk of smoking-related morbidity and the findings may be helpful to control them increase efficiency and work output. So, the present study is designed to assess the FEF25, FEF50 and FEF75 (L/sec) of adult smokers and compare the results with that of non-smokers.

\section{Materials and Methods}

This present cross-sectional study was carried out in the Department of Physiology, Dhaka Medical College, during the period of July, 
2007 to June, 2008. Permission was taken from concerned departments and authorities. Informed written consent was taken from all the study subjects after full explanation of nature and purpose of the study. The present study has been designed to measure FEF 25, FEF 50 and FEF 75 $(\mathrm{L} / \mathrm{sec})$ in apparently healthy adult male smokers and nonsmokers. In the present study 30 adult male smokers consuming cigarettes for more than 5 years selected as study group (Group-B) and were matched with 30 adult males who were non-smokers considered as control group (Group-A) for comparison. FEF25, FEF50 and FEF75 $(\mathrm{L} / \mathrm{sec})$ were estimated in both Groups. Analysis of data was done with the help of computer by SPSS 12.0 programmer and significant tests were done by unpaired Student's " $t$ " test.

\section{Results}

The mean $( \pm \mathrm{SD})$ age, height, weight and BMI in different groups of subject are shown in table I and the results are shown in table II. The mean ( \pm SD) of measured values of FEF $25(\mathrm{~L} / \mathrm{sec})$ is shown in Figure 1, the mean $( \pm \mathrm{SD})$ of measured values of FEF $50(\mathrm{~L} / \mathrm{sec})$ is shown in Figure 2 and the mean ( \pm SD) of measured values of FEF 75 $(\mathrm{L} / \mathrm{sec})$ is shown in Figure 3. FEF25, FEF50 and FEF75 $(\mathrm{L} / \mathrm{sec})$ significantly lower $(<0.05)$ in group A vs group B.

Table-I: Mean ( \pm SD) Age, Height, Weight, BMI of both subjects.

\begin{tabular}{lccccc}
\hline Group N & $\begin{array}{c}\text { Age } \\
\text { (Years })\end{array}$ & $\begin{array}{c}\text { Height } \\
(\mathbf{c m})\end{array}$ & $\begin{array}{c}\text { Weight } \\
(\mathbf{k g})\end{array}$ & $\begin{array}{c}\text { BMI } \\
\left(\mathrm{kg} / \mathrm{m}^{2}\right)\end{array}$ \\
\hline A & 30 & $\begin{array}{c}30.15 \pm 6.98 \\
(22-45)\end{array}$ & $\begin{array}{c}161.82 \pm 23.40 \\
(127-197)\end{array}$ & $\begin{array}{c}62.07 \pm 8.85 \\
(46-83)\end{array}$ & $\begin{array}{c}22.80 \pm 2.92 \\
(16.75-30.86)\end{array}$ \\
& & & & & \\
B & 30 & $\begin{array}{c}31.69 \pm 8.08 \\
(22-45)\end{array}$ & $\begin{array}{c}164.14 \pm 23.40 \\
(150-181)\end{array}$ & $\begin{array}{c}61.46 \pm 8.85 \\
(42-84)\end{array}$ & $\begin{array}{c}22.50 \pm 2.92 \\
(14.85-30.86)\end{array}$ \\
& & & & &
\end{tabular}

Table-II: Study parameters of the subjects in both groups $(n=30)$.

\begin{tabular}{llll}
\hline Parameters & Nonsmoker & Smoker & p value \\
\hline FEF 25 (L/S) & $6.74 \pm 1.76$ & $5.28 \pm 1.85$ & $0.003 * * *$ \\
FEF 50 (L/S) & $4.85 \pm 1.53$ & $3.27 \pm 1.58$ & $<0.001^{* * *}$ \\
FEF 75 (L/S) & $1.87 \pm 0.87$ & $1.36 \pm 0.94$ & $0.033^{*}$ \\
\hline
\end{tabular}

Results are expressed as mean \pm SD. Unpaired Student's ' $\mathrm{t}$ ' test was performed to compare between the groups. The test of significance was calculated and $p$ value $<0.05$ was accepted as level of significance.

$\mathrm{n}=$ number of participants

Values in parenthesis indicate ranges

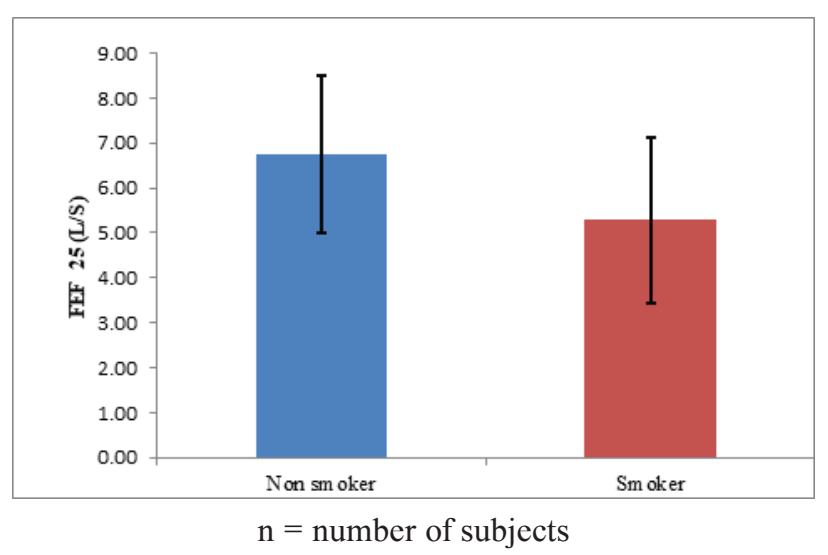

Figure-1: Mean FEF $25(\mathrm{~L} / \mathrm{S})$ in both groups $(\mathrm{n}=30)$.

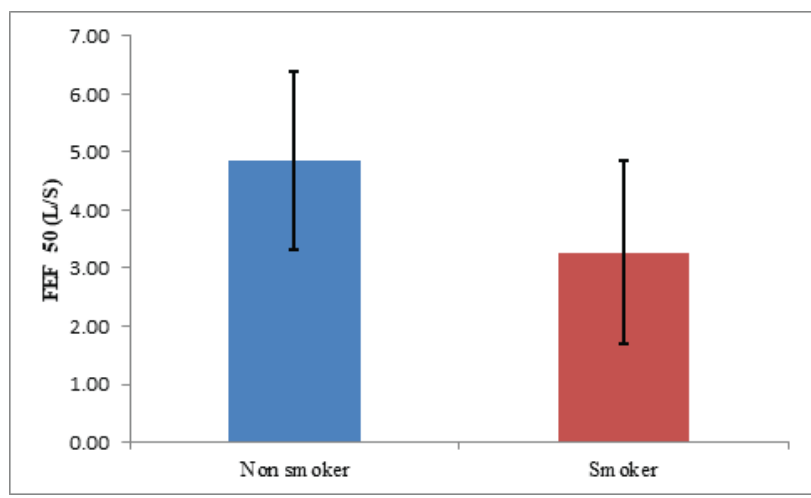

$\mathrm{n}=$ number of subjects

Figure -2: Mean FEF50 (L/S) in both groups $(n=30)$.

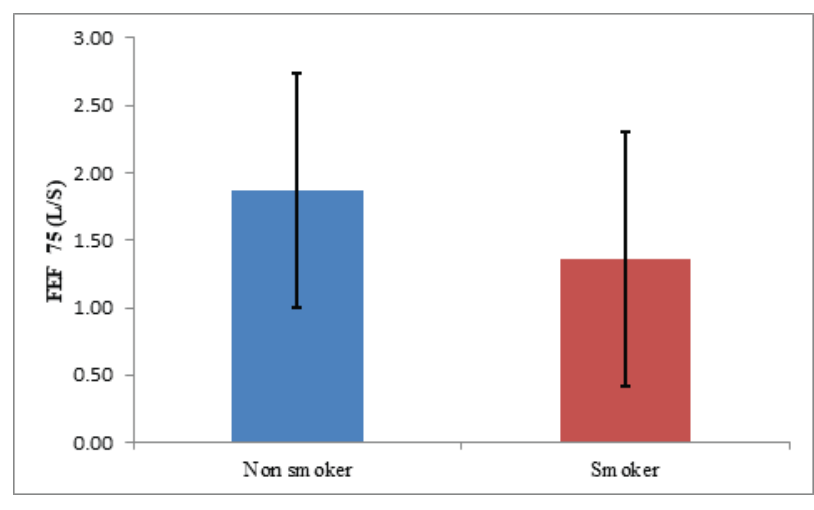

$\mathrm{n}=$ number of subjects

Figure-3: Mean FEF $75(\mathrm{~L} / \mathrm{S})$ in both groups $(n=30)$.

\section{Discussion}

The present study has been undertaken to compare the FEF25, FEF50, FEF75 (L/sec) in apparently healthy adult male smokers and nonsmokers. For this purpose, total 60 subjects age ranged from 22-45 years were selected. The participants were apparently healthy and from the different socio-economic classes. Age, height and weight of non smokers (control group) were matched with those of smokers (experimental group). In this study, spirometry 
was measured in smokers and nonsmokers. The accuracy of the results depends on full cooperation of the subjects. Care was taken to secure full cooperation of the subjects. Smoking history was recorded on a data collection sheet. Spirometry was recorded after the subjects were advised to put on loose clothes during experiment and abstain from smoking two hours prior to the test.

In present study, the mean ( \pm SD) FEF25 (L/sec) measured values were $6.74 \pm 1.76$ liter/sec and $5.28 \pm 1.85$ liter/sec in control and experimental group respectively. The difference of mean $( \pm$ SD) of FEF25 (L/sec) was statistically significant $(\mathrm{p}<0.001)$. This result is agreement with that of Jenith Berlin RajT ${ }^{7}$, Manikandan $\mathrm{S}^{8}$, D 1 DeMeo ${ }^{9}$. Jenith Berlin Raj $\mathrm{T}^{7}$ observed significant lower of FEF25 (L/sec) in apparently healthy male smoker's vs nonsmokers. FEF25 (L/sec) was reduced in smoking group. It is mostly the smaller airways than the larger airways which is affected due to smoking ${ }^{7}$. Manikandan $\mathrm{S}^{8}$ observed lower FEF25 (L/sec) in smoker causes both restrictive and obstructive pulmonary impairment. In the smoker's inflammation leads to permanent changes in the lungs ${ }^{8}$. D L DeMeo ${ }^{9}$ considered that FEF25 (L/sec) have been as evidence for small airway disease.

In present study, the mean ( \pm SD) FEF50 (L/sec) measured values were $4.85 \pm 1.53 \mathrm{liter} / \mathrm{sec}$ and $3.27 \pm 1.58$ liter/sec in control and experimental group respectively. The difference of mean $( \pm$ SD) of FEF50 (L/sec) was statistically significant $(p<0.001)$. This result is in agreement with that of Senthil kumar Elumalai ${ }^{10}$ and Anik Sukmawati ${ }^{11}$. Senthil Kumar Elumalai observed significant difference of FEF50 (L/sec) among non-symptomatic smokers \& nonsmokers. Senthil Kumar Elumalai stated that FEF $50(\mathrm{~L} / \mathrm{sec})$ appear to have its greatest utility in the diagnosis and monitoring of early, moderate disease \& has less value in following the case of severe disease ${ }^{10}$. Anik Sukmawati1 ${ }^{11}$ explained that reduction in FEF50 $(\mathrm{L} / \mathrm{sec})$ is associated with chronic cigarette smoking can be loss of lung recoil pressure which reduces the force driving air out of the lung ${ }^{11}$.

The mean $( \pm$ SD) FEF75 $(\mathrm{L} / \mathrm{sec})$ measured values were $1.87 \pm 0.87 \mathrm{liter} / \mathrm{sec}$ and $1.36 \pm 0.94 \mathrm{liter} / \mathrm{sec}$ in control and experimental group respectively. The difference of mean $( \pm$ SD) of FEF75 (L/sec) was statistically significant $(p<0.001)$. This result is consistent with that of Anand Mistry $^{12}$ and Ajay $\mathrm{K} \mathrm{T}^{13}$. Anand Mistry ${ }^{12}$ stated that decreased in FEF75 (L/sec) in smokers with increased duration of smoking \& increase in number of cigarettes smoked per day ${ }^{12}$. Ajay $\mathrm{K} \mathrm{T}^{13}$ suggested that young smokers within few years of starting to smoke developed changes in pulmonary functions indicating early peripheral airway narrowing and that these effects worsen progressively with continued smoking ${ }^{13}$. Meo SA ${ }^{14}$ concluded that tobacco smoking for 5 minutes causes an increase in impedance, peripheral airway flow resistance and oxidative sress.
Tantisuwat $\mathrm{A}^{15}$ stated that smoking habits and the number of cigarettes smoked per day were associated with the reduction in FEF25-75\%. Wafy s ${ }^{16}$ suggested that the most affected age group in significant reduction of FEF25-75\% was found in 36-55 years old adult male smokers. Coppeta $\mathrm{L}^{17}$ observed significant worsening of FEF $25-75 \%$ \& this parameter shown to be more sensitive than FEV1, FEV1/FVC ratio. They hypothesized that the decrease in the air flow is attributable to the acute increase of airflow resistance due to small airway narrowing depending on mucosal oedema, smooth muscle contraction \& local secretion. Malerba $\mathbf{M}^{18}$ suggested that abnormal FEF25-75\% considered a reliable marker of early airflow limitation. They pointed out that abnormal FEF25-75\% had a high probability of being bronchial hyper responsiveness, is probably due to eosinophilic airway inflammation.

\section{Conclusion}

From the statistical analysis of the results obtained in the present study and their comparison with those of published reports, it may be concluded that smoking causes significant deterioration of lung function which can easily detected by using a spirometer. FEF25, FEF50 and FEF75 (L/sec) are simple tests those could be useful in early diagnosis of peripheral airway obstruction and its treatment, thereby improving the quality of life.

\section{Conflict of Interest: None.}

\section{Acknowledgement}

The authors are thankful to the study subjects for their active, sincere and voluntary participation. The authors are also thankful to the Department of Physiology, Dhaka Medical College and Department of chest medicine, National Institute of Disease of the chest and hospital, Dhaka.

\section{References}

1.Nicnet. Nicotine and Tobacco Network. Encarta. 2003; 3(12): 325 .

2. Crapo RO. Pulmonary Function Testing. Text book of pulmonary Diseases. N Engl J MED. 1994; 331(1): 25-30.

https://doi.org/10.1056/NEJM199407073310107

PMid:8202099

3. Campbell IA. Crofton and Douglas's Respiratory Disease. 5th edition, England. Oxford. 2002: 311.

4. WHO, Tobacco or Health: A global status report, country profiles by Region, Southeast AsiaBangladesh.1995 http://www.cdc.gov/tobacco/WHO/bang lade.htm

5. Department of environment, 'Bangladesh Environment Conservation Rules', 1997, SRO-220 law.

6. Goren A I, Bruderman. Effects of occupational exposure and smoking and respiratory symptomatology and PFT in healthy panelists and COPD patient. European Journal of Epidemiology. 1989; 5(1): 58-64.

https://doi.org/10.1007/BF00145046

PMid:2707396 
7. Jeneth Berlin Raj T, Loganayak R, Raj Kumar D. Effect of cigarette smoking on forced expiratory volumes in asymptomatic smokers. IJCRR. 2013; 5 (10): 38-41.

8. Manikandan S, Anandnal Akhsmi S, Nageswari AD. Comparison of the effects of various modes of smoking on the pulmonary functions in healthy volunteers. AJPCR. 2015; 8(3): 289-91.

9. D L DeMeo, Vj Carey, H A Chapman. Familial aggregation of FEF25-75 and FEF25-75/FVC in families with severe early onset of COPD. BMJCAREERS. 2007; 59(5):1-13.

https://doi.org/10.1136/thx.2003.012856

PMid:15115866 PMCid:PMC1747013

10. Senthil Kumar Elumali, Arun G. Maiyo, Kalyan B Chakravarthy. Pulmonary function changes in asymptomatic smokers-a community survey in Udupi, Karnataka. India-International Journal of Research in Medical Sciences. 2017; 5(2): 653-658.

https://doi.org/10.18203/2320-6012.ijrms20170169

11. Anik Sukmawati, Muhammad Amin. Comparison of forced expiratory flow $25-75 \%$ values of smokers and non smokers. Journal Respiratory Indonesia. 2006; 369: 167-74.

12. Anand Mistry, Rajula Tyagi, Jaydeep Kagathara. Comparative Study of Pulmonary Function Tests in Smokers and Non Smokers. GCSMC J Med Sci. 2004; 3(1): 22-27.

13. Ajay K T, Bal PS, Smilee Jhony, Danyakumar G, Sangam. A comparative study of FEV1, FEF25-75 and PEFR in early adult smokers and non smokers. Int J Biol Med Res. 2012; 3(3): 1-2.
14. Meo SA, Ansary AM, Zia I. Electronic cigarettes: impact on lung function and fractional exhaled nitric oxide among healthy adults. American Journal of Men's health. 2018; 1:1-6.

https://doi.org/10.1177/1557988318806073

\section{PMid:30318975 PMCid:PMC6771130}

15. Tantisuwat A, Tnaveeratitham P. Effect of smoking on chest expansion, lung function and respiratory muscle strength of youths. Journal of physical therapy science. 2014; 26: 167-170.

https://doi.org/10.1589/jpts.26.167

\section{PMid:24648624 PMCid:PMC3944281}

16. Wafy S, Agmy G, Ali A. Early spirometric changes in asymptomatic smokers; is it a time dependent? European respiratory journal. 2016; 48: 1 .

https://doi.org/10.1183/13993003.congress-2016.PA4320

17. Coppeta L, Magrini A, Pictreiusti A. Effects of smoking electric cigarettes on pulmonary function and environmental parameters. The open public health journal. 2018; 11: 360-368.

https://doi.org/10.2174/1874944501811010360

18. Malerba M, Radeal A, Olivini A. Association of FEF 25-75\% impairment with bronchial hyperresponsiveness and airway inflammation in subjects with asthma like symptoms. Respiration. 2016; 91: 206-214.

https://doi.org/10.1159/000443797

PMid:26855322 